\title{
On the dynamics of social hierarchy: A longitudinal investigation of the rise and fall of prestige, dominance, and social rank in naturalistic task groups
}

\author{
Daniel J. Redhead ${ }^{*} 1,2$, Joey T. Cheng ${ }^{3}$, Charles Driver ${ }^{4} \&$ Tom Foulsham ${ }^{2} \&$ \\ Rick O'Gorman ${ }^{2}$ \\ *Corresponding Author: daniel redhead@eva.mpg.de. Current Address: \\ Department of Human Behavior, Ecology and Culture, Max Planck Institute \\ for Evolutionary Anthropology, Deutscher Platz 6, 04103 Leipzig, Germany. \\ ${ }^{1}$ Department of Human Behavior, Ecology and Culture. Max Planck \\ Institute for Evolutionary Anthropology, Leipzig. \\ ${ }^{2}$ Department of Psychology, University of Essex. \\ ${ }^{3}$ Department of Psychology, University of Illinois at Urbana-Champaign. \\ ${ }^{4}$ Centre for Lifespan Psychology, Max Plank Institute for Human Development, \\ Berlin.
}

Key Words: Prestige, Dominance, Social Hierarchy, Social Status, Power, Group Dynamics, Longitudinal Study.

Word Count: 8,025.

DJR: Generated the theory, designed the study, collected data, analysed data and drafted the first manuscript.

ROG: Generated the theory, designed the study and helped to draft the manuscript.

JTC: Designed the study, collected data and helped to draft the manuscript.

CD: Contributed to analyses, helped with interpretation of results and helped to draft the manuscript.

TF: Provided useful feedback throughout and helped to draft the manuscript.

Declarations of interest: none.

This research did not receive any specific grant from funding agencies in the public, commercial, or not-for-profit sectors. 


\begin{abstract}
The pursuit of social rank pervades all human societies and the position that an individual occupies within a hierarchy has important effects on their social and reproductive success. Whilst recent research has indicated that there are two distinct routes to rank attainmentdominance (through the induction of fear) and prestige (through respect and admiration) this empirical evidence has generally provided only a cross-sectional snapshot of how the two processes operate in human hierarchy. Whether dominance and prestige are potentially viable long-term strategies, rather than more effective short-term tactics, for acquiring rank in groups remains an open question. The current research addresses this gap by examining the temporal dynamics between prestige, dominance and social rank using a dynamic, evolutionary approach to understanding human social hierarchy, and thus supplies the first longitudinal empirical assessment of these variables' relationships. Using naturalistic student project groups comprised of 3-5 teammates, the present research tracks the temporal relationships between prestige, dominance and social rank - provided through round-robin teammate-ratings - from the initial formation of collaborative task groups through to the end of a 16-week long academic semester. Results indicate that, whilst dominance and prestige both promoted social rank in unacquainted groups initially and were distinct processes throughout the period examined, only prestige had a positive effect on social rank over time. Further results reveal that the temporal relationship between prestige and social rank was bidirectional, such that acquiring social rank further perpetuates future prestige. Overall, findings present a framework for the longitudinal distinction between prestige and dominance.
\end{abstract}

Keywords: Prestige; Dominance; Social Hierarchy; Social Status; Power; Group Dynamics; Longitudinal Study 


\section{Introduction}

Rank differentiation is ubiquitous in human societies, with social asymmetries being ever present within and between groups (Leavitt, 2005; Wiessner \& Schiefenhövel, 1998). Social rank is defined as an individual's or group's relative social influence and agency within a hierarchy (Anderson \& Kilduff, 2009a; Báles, Strodtbeck, Mills, \& Roseborough, 1951; Berger, Rosenholtz, Zeldtich \& Morris, 1980; Henrich \& Gil-White, 2001; Magee \& Galinsky, 2008). Throughout our evolutionary history social rank and outcomes of rank differentiation, such as leadership, have played important roles, determining group success and providing a platform for facilitating effective coordination, collective action and group decision-making (Glowacki \& von Rueden, 2015; O’Gorman, Henrich, \& Van Vugt, 2009). An emerging literature across the behavioral sciences indicates that variation exists in the origins and expression of rank differentiation in human groups (i.e. Borgerhoff Mulder, 1987; Hawkes \& Bliege Bird, 2002; Power \& Ready, 2018). Many forms of rank differentiation appear to be the result of conflict and imposition, but co-existing with this and also prevalent in human societies are hierarchies based on voluntary (freely conferred) deference (See Redhead, Cheng, \& O'Gorman, 2019, for further elaboration on freely conferred deference). How these distinct hierarchies emerge in human groups over time remains an unanswered question. By addressing such a question the current research provides substantial insight into why certain antecedents of social rank prevail in some groups yet appear redundant in others.

The current research provides a theoretical outline of, and tests, the dynamic, temporal relationships between prestige, dominance and social rank. We predicted that—in the current context — both profiles would be effective routes to attaining social rank during initial group formation, but the longitudinal trajectories of the two profiles would diverge with only prestige having an impact on social rank over time. The current context is 
characteristic of how many collaborative groups operate in WEIRD societies (Western, Educated, Industrialized, Rich, Democratic: Henrich, Heine \& Norenzaya, 2010), such as the increasingly flat, self-managed task groups that are prescribed no formal leadership, and are becoming increasingly prevalent in contemporary organizations (Bakker, 2010). These collaborative groups are comprised of individuals — who are often similar in age and have a similar level of educational attainment — focused on performing a specific task and exhibiting no formalized positions of power. Theory would suggest that in such groups dominance is likely to be countered (Boehm, 2009; Boehm \& Flack, 2010; Price \& Van Vugt, 2014; Van Vugt, 2006), resulting in unstable and thus potentially diminished longitudinal relationship to social rank. Consequently, in groups and societies that have developed strong norms that may either place a premium on prestige, or sanction dominance, the relationship that dominance has with social rank may be muted, whilst in groups and societies that lack these norms, dominance may remain an effective route to social rank (Pandit \& van Schaik, 2003).

\section{Dominance and Prestige: Two Routes to Social Rank}

Humanity draws on a deep phylogenetic history of individuals gaining rank through dominance: the strategic implementation of fear and coercion (Barkow, 1975). Individuals attend to a multitude of visual, auditory and behavioral cues to a peer's dominance, all of which may be signals of their ability to inflict harm and control resources (Maynard Smith \& Price, 1973; Mazur, 1985; Sell et al., 2009; Wrangham, 1980). Individuals not only attend to cues of a conspecific's ability to inflict harm, but also to signals of an individual's propensity for behaviors that propagate fear, which comprise a dominance psychological profile (i.e. aggression, disagreeableness, narcissism: Cheng, Tracy \& Henrich 2010; Henrich, 2016). 
Evidence suggests that dominance in humans provides some distinct fitness pay-offs. In certain contexts, males and females expressing dominance-related traits can be high in social rank and have control over social, sexual, informational and material resources (Buss \& Duntley, 2006; Chagnon, 2012; Cheng, Tracy, Foulsham, Kingstone, \& Henrich, 2013; Griskevicius et al., 2009). Complementary to this, meta-analytical evidence across nonindustrial societies indicates that dominance-conferring traits are linked to reproductive success (von Rueden \& Jaeggi, 2016). For example, males perceived high in dominance among Tsimane hunter-horticulturalists of Bolivia (von Rueden, Gurven, \& Kaplan, 2010) and males with lower voice pitch among the Hadza (Apicella, Feinberg, \& Marlowe, 2007) have a greater number of offspring within their community.

Whilst dominance does seem to predict social rank in some societies, contradictory evidence has emerged that suggests a zero or negative relationship between dominance and social rank in task-based groups (i.e. Anderson, Srivastava, Beer, Spataro, \& Chatman, 2006; Ridgeway \& Diekema, 1989). In such groups, dominant individuals may not possess exceptional instrumental social value and are neither willing nor able to facilitate the accomplishment of a group's shared goals. Individuals operating in collaborative groups are more likely to defer to conspecifics through processes of respect and esteem, rather than threat and coercion (Anderson \& Kilduff, 2009; Chase, 1974; Chase \& Lindquist, 2016; Price \& Van Vugt, 2014). Contradictory evidence is also found in small-scale societies, whereby dominance seems to relate to social rank in some groups (i.e. Chagnon, 1989; von Rueden et al., 2010), but not in others (i.e.Boehm, 2009; Cashdan, 1980; Kaplan, Hooper, \& Gurven, 2009). These inconsistent findings may in-part be due to the different ways that dominance has been operationalized, with measures of physical strength and size, fighting ability (especially in times of conflict) and authority potentially being confounded by perceptions of 
prestige, providing instrumental value and propagating respect-rather than fear-within a group.

This potential premium placed on respect, skill and esteem in collaborative groups likely emerged alongside humanity's increased interdependence for subsistence (Winterhalder, 1986), the increased reliance on social learning (Henrich \& Gil-White, 2001) and the enhanced need for coordination of collective efforts and leadership (Hooper, Kaplan, \& Boone, 2010; van Vugt, Hogan, \& Kaiser, 2008). Social rank derived from prestige refers to a process by which individuals preferentially defer to those who signal valued skills, knowledge and prosocial attributes (Bliege Bird \& Smith, 2005). Individuals also weight a potential learning model's prestige by assessing the attention and respect that they receive from proximate others (Henrich \& Broesch, 2011; Henrich \& Gil-White, 2001). Alongside this, groups are often attentive to cues of an individual's generous intent, signaling a propensity to effectively and equitably coordinate the group's actions (Glowacki \& von Rueden, 2015; Willer, 2009). Individuals confer deference and yield decision-making to these prosocial, talented individuals in an attempt to gain proximity and access the resources — be they informational, social or material — that the individual harbors (Cheng et al., 2013; von Rueden et al., 2014). This, in turn, creates an exchange-like relationship whereby the associated costs for information sharing and cooperation for the individual high in prestige — of which benefit the other members of the group — are outweighed by the benefits that they receive from being high in social rank (Bliege Bird \& Smith, 2005; Willer, 2009).

It is likely that humans have developed a prestige psychology, which encompasses a wide range of emotions and personality traits that are associated with both being and finding an optimal learning model, with individuals signaling and attending to both an ability and 
willingness to confer benefits (Cheng et al. 2010; Henrich, 2016). These prosocial reputations relate to the amount of socio-economic support and deference an individual receives (Hardy \& Van Vugt, 2006; Macfarlan, Quinlan, \& Remiker, 2013) and are crucial for prestige to be a stable strategy, as behaving arrogantly or with entitlement may squander away a prestigious individual's status (Ames \& Flynn, 2007). This is due to the market-like relationship that underpins prestige, as prestigious individuals do not take social rank with force, but are afforded social rank by others and are freely granted distinct fitness-enhancing benefits (i.e. higher reproductive success, positions of leadership: Alden Smith, 2004; Henrich \& GilWhite, 2001; von Rueden \& Jaeggi, 2016).

\section{The Longitudinal Dynamics of Social Hierarchy}

Although the extant literature indicates that dominance and prestige are both fruitful for attaining social rank in either unacquainted or pre-existing groups, extant theoretical and empirical research has not outlined the impact that time has on these processes. In the following section, we propose a theoretical framework that integrates time into the dual model of social hierarchy, hypothesizing that time may further give rise to a longitudinal distinction between the two processes and their relationship with social rank. We further highlight that whilst prestige and dominance are universal strategies for acquiring social rank, the relative context-specificity of rank allocation norms produces context-specificity in the efficacy of both dominance and prestige for the accrual of social rank.

Social hierarchy and rank relations are inherently dynamic and, in part, context specific. While social hierarchy is thought to be universal (Van Vugt \& Tybur, 2015), there are striking differences in the extant cross-sectional evidence examining the antecedents and dimensions of rank differentiation (reviewed in Ridgeway, 2017). It seems that, while we all 
have a motivation to obtain social rank and feel valued (Anderson, Hildreth, \& Howland, 2015), the means by which these positions are obtained may be culturally and contextually determined (Benoit-Smullyan, 1944; Henrich \& Gil-White, 2001; Leary, Jongman-Sereno, \& Diebels, 2014). Individuals operate in multiple hierarchies in their day-to-day lives. They may be the head of their household, but subordinate in their network of friends or coasting as the middle man in their workplace, with each hierarchy operating on a distinct set of rules for rank allocation (Sewell, 1992). These rules may be governed by the social dynamics of the group, with rank allocation norms being contingent on the relational nature of deference within the group. More specifically, the deference behaviors of group members are in response to the actions and traits observed in those around them. Through this reactive relational dependence, those composing a group often infer whether an individual is worth deferring to by attending to the deference behaviors of others (Chudek, Heller, Birch \& Henrich, 2012) and, in turn, confer social rank to the same individuals (Báles, Strodtbeck, Mills, \& Roseborough, 1951; Blau, 1964; Zaccaro, 2007). The norms surrounding rank allocation may further be guided by the task that a group faces, operating in a manner that may maximize group success (Ellis, 1994; C. Ridgeway \& Diekema, 1989) or reduce the costs inflicted upon the group by others (Cheng \& Tracy, 2014; Mazur, 2005).

However, differences between contexts may need time to become salient. In the nascent stages of group formation, or in transient groups of unacquainted individuals, rank asymmetries may be unstable and the norms surrounding the traits that promote social rank are, in most cases, unclear. Therefore, in such groups, rank allocation patterns may differ from those observed in long-term groups. Given the relational nature of deference in groups, time is important as it facilitates observations of who other members of the group are attending and deferring to. This may notably operate within the confines of the perceiver's local network neighborhood, with individuals evaluating the behaviors of those who they 
have first- or second-degree relationships with. Evidence confirms that reputation correlates more strongly with history of acts and behaviors for the most prominent individuals in a community (Anderson \& Shirako, 2008). Over time, the relationship between contextuallyimportant traits and social rank within a group is not only expected to strengthen, but also be dynamic, with anterior social rank increasing future social rank and potentially feeding back into and increasing perceptions of the processes that increased social rank previously. These dynamic aspects of rank differentiation would suggest that the processes relating to rank acquisition may have divergent impacts on social rank in the different stages of group formation.

Given that individuals high in dominance gain social rank through fear, it is easier for dominance to operate effectively in the nascent stages of group formation, or in transient groups of unacquainted individuals. Evidence suggests that humans possess evolved cognitive capacities for extracting formidability-relevant information from both morphological and behavioral signals to dominance (Holbrook, Fessler, \& Navarrete, 2016; Sell et al., 2009). Those high in dominance are also likely to cue social formidability and are more inclined to speak and attempt to forcefully direct group-related tasks. For example, dominant individuals are prone to deepen their voice during initial interaction, speak with force and subtly tease or ostracize others to produce fear (Bendersky \& Hays, 2011; Brass \& Burkhardt, 1993; Case \& Maner, 2014; Cheng, Tracy, Ho, \& Henrich, 2016; Keltner, Young, Heerey, Oemig, \& Monarch, 1998; Manson, Gervais, Fessler, \& Kline, 2014). Through these behaviors, the individuals who become more conversationally domineering and interrupt during task-related conversations are perceived higher in dominance and, in turn, higher in social rank in groups of unacquainted individuals (Cheng, Tracy, Foulsham, Kingstone, \& Henrich, 2013; Farley, 2008). This evidence suggests that, unlike prestige, the efficacy of 
dominance in promoting social rank is less reliant on a history of interactions and that cues to dominance may be salient even with limited information.

It is possible that temporally-extended group interactions will mitigate the effectiveness of dominance. Human groups accurately monitor status dynamics and the behavior of individuals, which may suppress the effects of dominance on rank acquisition over time (Anderson et al. 2001; Boehm \& Flack, 2010; Wiessner \& Schiefenhövel, 1998). For example, as group members become acquainted with one another and exchange information and experiences, the perceived value of members develops (Baumeister, Zhang, \& Vohs, 2004; Feinberg, Willer, \& Schultz, 2014). Individuals who initially attained social rank due to dominance behaviors may not be perceived as high in social capital or instrumental social value (i.e. both their ability and willingness to help accomplish an individual's or group's goals: Leary et al., 2014; Lin, 1999). Specifically, cross-sectional evidence suggests that in task-groups of individuals cooperating to accomplish a shared goal, perceptions of an individual's allocentric (other-oriented) motives, generosity and taskrelated competence are most salient in promoting social rank (Anderson \& Kilduff, 2009a; Flynn, Reagans, Amanatullah, \& Ames, 2006; Griskevicius et al., 2009), which are traits antithetical to those associated with dominance (Cheng, Tracy, \& Henrich, 2010).

We propose that the context of time and place is fundamental to the nature of human dominance, with dominance relations being malleable based on the composition of group. Unlike non-human primates, physical strength and size are not necessarily the most essential determinants of victory during agonistic contests between humans. The presence of allies and coalitions shrinks the perceived size and muscularity of a foe (Fessler \& Holbrook, 2013; Holbrook, Fessler \& Navarrete, 2016) and the widespread development of lethal weaponry potentially neutralizes human physiological dominance (Gintis, van Schaik, \& Boehm, 2015). 
The diminished potency of physical dominance, and increased reliance on manipulation (Clutton-Brock, 2009) and coercion through psychological fear (Henrich \& Gil-White, 2001) has altered the manifestation of dominance relationships. This, paired with the aforementioned temporal dynamics associated with rank allocation and maintenance, has constrained the efficacy of dominance as a long-term strategy for attaining social rank in many settings.

For dominance to remain an effective rank acquisition strategy over time, there must be a number of social and socio-structural antecedents. Within groups where aggression, bullying and violence are prevalent and normative, individuals high in dominance-related traits may take power and increase their rank (Decker \& Van Winkle, 1996; Henry et al., 2000; Redhead 2016). In developmental hierarchies, for instance, dominance is associated with popularity and social rank (Redhead, Cheng, \& O'Gorman, 2018) and seems most potent for rank acquisition during periods of transition (i.e. between primary and middle or junior high school), when groups and hierarchies are forming (Faris \& Felmlee, 2011; Pellegrini \& Long, 2003). Moreover, in periods when usually peaceful groups are warring, individuals perceived high in dominance may be preferentially selected as leaders (Little, Burriss, Jones, \& Roberts, 2007). A similar partiality for leaders harboring dominance-related traits has also been observed in formalized hierarchies, whereby the official position of an individual may afford them power and the increased ability to inflict costs on others via reward and punishment (Magee \& Galinsky, 2008). In sum, the efficacy of dominance is expected to be less stable and more variable across environments.

Prestige, on the other hand, seems to be universally promoted by groups and communities, and should remain a near-universal stable and effective route for attaining social rank over time. Prestige is marked by the deference of others within the group and may 
become more potent in promoting rank when greater information is gathered, or needed, about a potential learning model. There seems to be an innate ability to track and preferentially learn from accurate models (Birch, Vauthier, \& Bloom, 2008). Thus, prestige may have an impact on social rank during a group's initial meeting. However, during this initial phase of a group's formation all individuals are relatively naïve learners and may not be able to precisely understand a causal connection between a potential learning model's practices and their success (Henrich, 2016). Their judgements about a potential learning model's prestige may rely on less accurate cues to their adaptive knowledge suitable for the given situation, such as attribute-similarity (Losin, Iacoboni, Martin, \& Dapretto, 2012) and cross-domain prestige biases (e.g. being carried over from an unrelated field: Henrich \& GilWhite, 2001). This, paired with the amount that potentially dominant others speak and interrupt, are attended to, and are afforded social rank in the initial period of a group's formation may cause these cues to prestige to be weaker in the nascent stages of group formation.

This is not to say that prestige is an ineffective process among unacquainted groups, nor that prestige is constrained solely to social learning, but that prestige may become increasingly effective as group members become more acquainted and there are more opportunities to directly perceive success as well as indirect cues to prestige. Additionally, prestige is founded on the desire of others within the group to please prestigious learning models, which is cued by the proximity that peers strive for and maintain, and the deference that these individuals provide (Henrich \& Gil-White, 2001). Consequently, the accumulation of deference that a learning model receives and the growing number of proximate others talking positively about them, wanting to be close to and mimicking them may also feed back into the individual's future prestige (Chudek, Heller, Birch \& Henrich, 2012). Thus, through 
a learners' tendency to track prestige cues given off by other learners (i.e., to whom do others attend, defer, and emulate), social rank and prior prestige breed greater future prestige.

\section{The Current Research}

Given the theoretical grounds for suspecting that dominance may lead to social rank in the early stages of group formation but yield to prestige over time, we designed a study using newly-formed task-based student groups to directly assess the outlined temporal dynamics of the dual model of social hierarchy. We predict that in the current context prestige and dominance will have distinct temporal effects on social rank in collaborative task groups, but over time these relationships will be bidirectional and social rank may also impact on an individual's perceived prestige, but not dominance. The current study utilizes peer ratings of prestige, dominance, and social rank within task-based groups for which membership was randomly determined. The timescale of the present research (a 16-week semester) captured the measures from the stage of group formation through to the completion of the task that the group faced. The current context provides a fruitful platform for evaluating the effects of prestige and dominance, as a sizable collection of individuals collaborated on projects that had a substantial impact on their academic grade — an outcome that is given substantial weight in this model group. Thus, individuals had a vested interest in ensuring that the group functioned effectively, which parallels the dynamics of a wide range of project-based groups that represent how many far-reaching, crucial decisions are made (i.e. work groups and teams in organizations, leaders and policy-makers in government: Anderson \& Kilduff, 2009a; Ronay, Greenaway, Anicich, \& Galinsky, 2012) in WEIRD societies (Western, Educated, Industrialized, Rich, Democratic: Henrich, Heine \& Norenzaya, 2010). 


\subsection{Hypotheses}

In light of previous evidence and the theory outlined above we hypothesized that in the current context:

H1: Prestige and dominance both predict social rank at the initial time of measurement.

H2: Whilst individuals perceived as high in dominance will have high social rank initially, this relationship will diminish over time.

H3: Individuals perceived as high in prestige will have relatively high social rank initially and this relationship will strengthen over time.

H4: Individual's social rank will feedback and increase their subsequent prestige.

H5: Prestige and dominance will operate independently as distinct processes, such that they will be neither correlated nor impact one another, throughout the study.

\section{Method}

5.1. Participants. $\quad$ Students $(N=263,60 \%$ female, $\bar{x}$ age $=20.67, S D=1.38$, Age Range $=18-28)$ at a North American University participated in exchange for course-credit. Participants comprised two classrooms enrolled in the same course taught by the same instructor over two years (classroom 1: $n=123$ individuals, classroom 2: $n=140$ individuals), and were nested in 66 randomly assigned mixed-sex task groups (classroom 1:n $=30$ groups, classroom 2: $n=36$ groups) that each had between 3-5 members $(\bar{x}=$ 
$4.02, S D=0.33)$. Participants worked in the task groups to complete a course project throughout the 16 -week semester worth $30 \%$ of their final grade.

5.2. Procedure. Every week, participants attended a large lecture for two hours and spent a further four hours working in-person in their randomly-assigned task groups in laboratory sections. At the start of the semester, participants completed a self-report questionnaire in week 1 , before meeting the rest of their group. In the remainder of the semester, they completed a further four self- and peer-report questionnaires (in weeks 2, 6, 10 and 16) online. The extra two weeks between the fourth and fifth questionnaires (weeks 10 and 16) were due to the week-long holiday and mid-term exams during this period. Participants were assigned a unique ID and allotted up to 7 days to complete each questionnaire.

\subsection{Self-Report Measures.}

Gender. Participants reported the gender that they identify as at the beginning of the study (week 1). Participants were given the choice of 4 categories: 'male', 'female', 'neither male nor female' and 'prefer to not say'.

\subsection{Peer-Report Measures.}

Prestige and Dominance. Throughout the peer-report questionnaires (weeks 2, 6, 10, 16), participants rated all other members of their task groups on prestige and dominance, using an abridged version (in order to reduce participant fatigue) of the Prestige and Dominance Scaled Questionnaires (Cheng et al., 2010). All ratings were made on a scale ranging from 1 (Strongly Disagree) to 7 (Strongly Agree). Ratings comprised four items assessing perceived 
prestige (e.g. "Their unique talents and abilities are recognized by others in the group") and four items measuring perceived dominance (e.g. "They enjoy having control over other members of the group"). Ratings were then averaged across raters at each time wave to obtain prestige and dominance scores for each participant. Table 1 shows descriptive statistics for all variables. Both prestige and dominance had excellent reliability, with $\alpha>.80$, and were not correlated at every time point (see Supplementary Materials for internal consistency, relation to the full scales in a subset of the sample, and bivariate correlations between all variables at each time point).

Social Rank. Prior work has used and established the validity of this set of items in predicting actual decision-making capacity within groups (Cheng et al., 2013). Here, participants rated all other members of their group on three items assessing perceived social influence and three items assessing their perceived agency. The items capturing social influence comprised: "This person leads the task group", "I paid attention to this person" and "This person had high status". The items capturing agency were adapted from the Revised Interpersonal Adjective Scale (Wiggins, Trapnell, \& Phillips, 1988) and consisted of: “This person was assertive", "This person was self-confident" and "This person is timid". Responses across all 6 items were averaged at each time wave to yield a composite score for their perceived social rank that had adequate internal consistency at every time-point (see Supplementary Materials).

\subsection{Analytical Strategy}

We assessed the dynamic relationships between prestige, dominance and social rank from the point that the collaborative task groups formed and cast initial peer ratings (week 2 of the study, referred to as $T_{1}$ from this point) to the end of the semester (week 16 , referred to 
as $T_{4}$ ) using a hierarchical Bayesian continuous-time structural equation model (from this point referred to as ctsem: for an introduction see Driver \& Voelkle, 2018), using the ctsem package (version 2.4.0. Driver, Oud, \& Voelkle, 2017) in R (version 3.3.3: R core development team). ctsem utilizes stochastic differential equations that assess processes operating continuously over time and accounts for a number of important short-comings of typical discrete time models (see Driver, Voelkle \& Oud, 2017; Driver \& Voelkle, 2018). A central strength of ctsem is that hypotheses relating to how change in one process may predict later change in a different process (i.e. cross-lagged effects) are assessed while accounting for stable factors, such as the average level of the process, and also correlated changes at that time point (via the diffusion matrix, see Driver et al., 2017). Through a hierarchical Bayesian framework, ctsem allows for the estimation of continuous time processes of a sample while accounting for potential subject-level deviations by using population model estimates to inform subject-level model priors, which is a fruitful compromise between more traditional fixed-effects and subject-specific models (see Driver \& Voelkle, 2018). See supplementary materials for more information about the modelling approach.

The ctsem that was applied to our data represents a first order, three-process model of prestige, dominance and social rank dynamics. We specified a mixed effects model with random manifest means but fixed regression and variance parameters, and retained the default model priors outlined in Driver and Voelkle (2018). Whilst we did not predict effects of gender, gender composition of groups, size of group and cohort, we ran models that controlled for the potential main effects of these variables on the average level of model processes by including them as time-independent predictors. In fact, none of these variables had an impact on any processes, nor did they improve model fit. Moreover, to assess and account for any interdependencies in ratings of prestige, dominance and social rank at the task-group level, a model was estimated where prestige, dominance and social rank were 
group-mean centered. This also had no impact on our results. Outputs from any of these models are available upon request. Figure 1 illustrates the final estimated model and Equation 1 represents the matrix specification of our subject-level model.

The focus of the model was the drift matrix of temporal dynamics, represented in Figure 1 as regression paths between dominance, social rank and prestige, and the diffusion matrix, which is represented as the correlations between prestige, dominance and social rank at a given time point. The drift matrix illustrates the lagged interrelatedness of the processes on one another (e.g. the effects of dominance at time 1 on social rank at time 2), and the within-subject temporal stability (i.e. the auto effects of prestige on prestige over time). The diffusion matrix represents uncertainty, or noise, in the dynamic model - at any time there may be changes occurring in the latent processes that the deterministic dynamics given by the drift matrix do not predict, and these random changes can be correlated across processes. In interpreting the model outputs, we assessed the parameter's posterior mean in relation to its posterior standard deviation (SD) and posterior credibility intervals (CI). The CI indicate, with $95 \%$ credibility, the probability that the parameter falls between the lower $(2.5 \%)$ and upper (97.5\%) limits. For some parameters it is important to consider if they genuinely differ from zero - for these, if zero does not fall within the upper or lower limits the CI of the parameter, then we conclude that the non-zero parameter estimate is not due merely to sample fluctuations, but is relevant for interpretation.

\section{Results}

\subsection{Do dominance and prestige predict social rank initially in the newly formed groups} (H1)? 
To examine the impact of perceived prestige and dominance on social rank at the initial time of measurement, we examined the partial correlations between all three variables at the initial point of the groups meeting (see Figure 2). We specified a uniform prior on the space of correlation matrices (Lewandowski, Kurowicka \& Joe, 2009). Estimation was carried out using R package Stan (Stan Development Team, 2018). We used a NUTS (No UTurn: Hoffman \& Gelman, 2011) sampler with 4 chains and 2000 iterations. All parameters had above 3700 effective samples and an $\widehat{R}$ of 1.00 , indicating appropriate model convergence.

There were no significant differences in perceptions of prestige, dominance and social rank based on gender. Nor were there any substantial gender differences in the relationship between prestige, dominance and social rank when assessing males and females separately. Thus, the correlations reported are collapsed across genders. Correlations were consistent with Hypothesis 1 and suggest that at time 1 prestige had a strong, positive relationship with social rank with the $95 \%$ credibility intervals being much greater than zero $(\rho=0.32, C I=$ $[0.20,0.43])$. A positive relationship was also found between dominance and social rank $(\rho=$ $0.20, C I=[0.08,0.32])$. See Figure 2 for a full partial correlation matrix and Electronic Supplementary Materials for a bivariate correlation matrix for the same parameters.

\subsection{Do prestige and dominance predict social rank over time (H2 and H3)?}

The results presented in Table 2 are the posterior mean, standard deviation and CI estimates of the means of the population distributions of the model represented by Figure 1. All parameter estimates reported have far greater than 100 effective samples and the $\widehat{R}$ for all parameters fell between $1.00-1.03$. As shown in Table 2, there were no notable main effects 
of gender on the average levels of the three processes, with the credibility intervals encompassing 0 .

The population means for the $T_{0}$ mean parameters in Table 2 represent the relationship between the subject's initial states with their later states throughout the latent process. A negative $T_{0}$ mean implies that the initial state of the process was lower than future states, whereas a positive value would suggest that the initial state was higher. Results indicate no strong tendency for prestige $(\bar{x}=-0.82, S D=0.54, C I=[-1.73,0.65])$, dominance $(\bar{x}=0.19, S D=1.20, C I=[-1.54,3.72])$ or social $\operatorname{rank}(\bar{x}=-0.66, S D=$ $0.57, C I=[-1.07,0.85])$ to increase or decrease substantially over time, as for all parameters zero falls within the CIs. The manifest mean parameters represent the average level of the processes, reflecting the intercepts of prestige, dominance and social rank. The manifest variance parameters reflect random measurement error in the indicators of prestige, dominance and social rank. The manifest variance between prestige and social rank are at a similar level (see Table 2), indicating that measurement error made similar contributions to the variance observed in both processes. Measurement variance in dominance is considerably higher than the other processes, which suggests that limitations associated with our measurement and potential short-term situational influences contributed more to the variance observed in dominance than in the other processes. These results do not suggest that the current measures are unreliable. Rather, they reflect the observed within-person variability.

The drift parameters of prestige on prestige, dominance on dominance, and social rank on social rank denote the autoregression effects of the processes. The closer these estimates are to zero, the more temporal stability there is in the process - that is, changes in prestige, dominance and social rank persist longer in time. As shown in Table 2 and Figure 3a, changes in dominance persist, as the estimates are closest to zero $(\bar{x}=-0.23, S D=$ 
$0.16, C I=[-0.59,-0.02])$. Changes in social rank are the next most persistent $(\bar{x}=$ $-0.66, S D=0.19, C I=[-1.07,-0.32])$, while changes in prestige appear to dissipate fastest $(\bar{x}=-1.07, S D=0.22, C I=[-1.52,-0.66])$.

To assess the effects of prestige and dominance on social rank over time we first evaluate the drift matrix parameters that represent the cross effects in Table 2 and are shown in Figures $3 b$. When a positive value is estimated it reflects that when one process rises, so too does the other, whereas a negative value would suggest a negative effect. Results support Hypothesis 3 , indicating that prestige had a positive effect on social rank over time $(\bar{x}=$ $0.33, S D=0.15, C I=[0.05,0.66])$. Consistent with Hypothesis 2, evidence for the effect of dominance on social rank over time is less clear, with results indicating that there was no substantial effect, with CI's including zero $(\bar{x}=0.12, S D=0.12, C I=[-0.09,0.38])$.

To further understand the temporal relationships that prestige and dominance have with social rank, we turn to the diffusion matrix correlation parameters shown in Table 2. Unlike the results above, which present the cross-lagged temporal relationships between processes, these parameters represent the within-subject correlation in the random changes of the latent processes and highlight the extent to which the processes may share common causes. The results align with those of the drift parameters, providing strong evidence that the random changes in prestige and social rank over time may share some common causes $(\bar{x}=$ $0.71, S D=0.12, C I=[0.46,0.90])$. Random disturbances affecting dominance and social rank processes do not seem related $(\bar{x}=-0.03, S D=0.12, C I=[-0.25,0.20])$.

Furthermore, the between-subject parameters - indicating the between-subjects temporal correlations between prestige, dominance and social rank across the study — shown in Table 2 indicate that average levels of prestige had a high correlation with average levels 
of social rank $(\bar{x}=0.78, S D=0.12, C I=[0.42,0.90])$. Whereas, the near-zero betweensubject correlation for dominance and social rank indicate average levels of the processes tended to have a limited correlation $(\bar{x}=-0.02, S D=0.20, C I=[-0.48,0.31])$. With respect to our hypotheses about the temporal effects that dominance has on long-term social rank $(\mathrm{H} 2)$, results are inconclusive - if dominance does have an effect, it is not substantial in this sample or context.

\subsection{Does social rank increase prestige, but not dominance, over time (H4)?}

To assess the concurrent effects of social rank on prestige and dominance over time, we examined the drift matrix parameters in Table 2 and Figure $3 \mathrm{c}-\mathrm{d}$ that illustrate the processes' cross effects. Results provide evidence in support of Hypothesis 4 and imply that social rank markedly increases an individual's prestige over time $(\bar{x}=1.10, S D=0.23, C I=$ $[0.66,1.58])$, to a greater extent than prestige affects social rank (see above). This is suggestive of a feedback process of an individual's social rank on their future prestige. On the other hand, the effect of social rank on dominance was negligible $(\bar{x}=-016, S D=$ $0.15, C I=[-0.11,0.47])$. As outlined above, both the between-subject correlations and diffusion matrix correlations between prestige and social rank were positively related, while the between-subject correlations and diffusion matrix correlations between dominance and social rank indicate little to no relationship. The results support our hypothesis suggesting that social rank only impacted an individual's future prestige, whilst it had no detectible effect on dominance.

\subsection{Are prestige and dominance distinct temporal processes (H5)?}


As shown in Figure 2, prestige and dominance were not substantially correlated at any time point in the study. Both of these results are consistent with Hypothesis 5.

The drift parameters and diffusion matrix correlations between prestige and dominance assess the interrelatedness of changes in the processes over the observed time range, while the correlation between the average level of the processes points to their relation in a crosssectional sense. As shown in Table 2 and Figure 3c-d, all such parameters include zero in the $C I$, providing evidence in support of Hypothesis 5 and suggesting that if there is a relationship between prestige and dominance, it is not as substantial as that between other processes discussed. Results support our hypothesis that, whilst prestige and dominance tended to have a negative impact on one another, the relationship was limited, and they may operate as independent processes.

\section{Discussion}

The current research extends prior work on human social hierarchy by proposing a theoretical account of how prestige and dominance fare over time. We also provide the first longitudinal empirical assessment of the hypothesized dynamic relationships. Through a longitudinal task-group design the present research examined the unique effects that prestige and dominance had on social rank from the initial formation of collaborative groups through to the completion of those group's tasks using an advanced analytical technique. In line with previous research (Cheng et al., 2013), results replicate that both prestige and dominance coexisted as successful rank acquisition strategies in newly acquainted groups. These results align with previous work that suggests that humans have a predisposition to defer to those that they perceived as able and willing to either confer benefits or inflict harm, even among groups of undergraduate students, whereby fear and threat may not be particularly potent. 
Critically, however, in the weeks following group formation, dominance did not have a substantial effect on social rank, whilst prestige strongly increased social rank over time. The present findings also demonstrated that the relationship that prestige had with social rank was bidirectional, with an individual's social rank having a positive temporal effect on prestige. Finally, results support the notion that prestige and dominance are distinct processes, with neither process having a substantial temporal impact on one another and random disturbances on the two processes having a limited correlation.

The current research highlights that time is of both theoretical and methodological importance in the assessment of processes relating to social hierarchy. The present findings supported the prestige-dominance account of human social hierarchy and further highlight the complexities of human rank attainment and maintenance over time. Specifically, we argue that in collaborative task-based groups, which is a relatively generalizable context in WEIRD societies, there is a premium placed on prestige, such that prestige maintains an individual's social rank whilst social rank further increases their prestige. This relationship is important for the interpretation of cross-sectional assessments of the relationship between prestige and social rank. Cross-sectionally, a significant relationship between the two processes in previously acquainted groups is often interpreted as prestige impacting social rank. However, the present research highlights that these cross-sectional findings should be interpreted with caution as the converse relationship may in fact be what they are observing. The following section outlines the broad implications of the current research for understanding social hierarchy and rank allocation in human groups.

\subsection{Implications for the Dual Model of Social Hierarchy}


The dual model of social hierarchy outlines that, in human hierarchies, individuals may attain social rank through prestige and dominance (Henrich \& Gil-White, 2001). Expanding upon this, the current research provides a theoretical framework for the distinction between these two processes over time demonstrating that dominance and prestige have no substantial within-person temporal relationship or between-subject correlation throughout the period observed. This finding stands in contrast with the concept that social rank acquired through dominance is only made viable as the cues to dominance are misinterpreted by peers as indications of prestige-related traits, such as competence (Anderson \& Kilduff, 2009b; Chapais, 2015; Lukaszewski, Simmons, Anderson, \& Roney, 2016). These results provide clear indication that dominant individuals are not simply confused as prestigious, neither concurrently nor over time. Rather, the current findings support that individuals in unacquainted groups may attain rank through two distinct, concurrent routes either centered on producing fear through aggression and coercion or obtaining respect through skill and competence (Cheng et al., 2013, 2010; Sijtsema, Veenstra, Lindenberg, \& Salmivalli, 2009). Importantly, the present findings indicate that prestige and dominance have divergent temporal relationships with social rank, with prestige having a strong, positive and sustained relationship with social rank, whilst the effect that dominance has on rank attainment, in this context, is negligible over time.

The question raised by these results, therefore, is not whether dominance is a successful rank acquisition strategy but when. In which contexts and at what times in an interaction is dominance a viable route to acquiring and maintaining social rank? In the nascent stages of group formation, the context-dependent norms that constrain dominance may have limited potency for two reasons. Firstly, dominance-related traits and behaviors may be incredibly effective in newly-formed groups, signaling their threat potential and allowing them to acquire rank among unacquainted individuals who have limited cues to 
attend to (Bruckert, Liénard, Lacroix, Kreutzer, \& Leboucher, 2006; Cheng et al., 2016; Farley, 2008; D. R. Feinberg, Jones, Little, Burt, \& Perrett, 2005). Secondly, previous research has indicated that leveling mechanisms that may produce such context-dependent norms, for example coalitions, negative gossip and group sanctions, monitor behaviors and supress the relationship between dominance and social rank (Boehm, 2009; Dunbar, 1996; Feinberg, Willer, \& Schultz, 2014). Unacquainted individuals do not have high degrees of relational closeness and may not be able to or feel comfortable to discuss an absent other as part of monitoring and gossip (Burt \& Knez, 1996; Dunbar, 1996), thus the potency of these leveling mechanisms would be limited. The current research highlights that these norms may come into fruition only once individuals have become better acquainted and that suggests that the levelling mechanisms underlying such norms may explain the present finding that dominance is effective only in the initial period and not over the entire period of study. Directly assessing the emergence and success of a vast array of leveling efforts aimed at preventing coercive leadership, in order to understand why certain individuals manage to acquire and retain influence over time through force and fear and why some groups succeed (while others fail) in leveling dominance, remains an important and open area for future inquiry.

Antithetically, the present findings offer the first empirical evidence indicating that, whilst prestige is related to social rank among unacquainted individuals when groups initially form, this relationship remains strong over time. These results support the theoretical account outlining that prestige-based social rank may have developed dynamically alongside the remarkable capacity for cultural learning that humans exhibit, with cultural learning providing an opportunity for prestige-based rank and also being propagated by prestige (Boyd \& Richerson, 1988; Henrich \& McElreath, 2003). Among unacquainted individuals, those assessing who to learn from, and support or cooperate with, are relatively naïve and 
may attend to cues that are weakly associated to an individual's skill, knowledge and ability (Henrich, 2016). At the same time, dominance may operate effectively, with those high in dominance commanding the attention of others. However, once individuals collect more information about their peers over time, more robust impressions of an individual's prestige can form, which are based on repeated observations of cues to both their ability and to a cooperative, prosocial disposition. Moreover, the extremely high continuous-time betweensubjects correlation and raw discrete-time correlations observed in the present study indicate that, over time, prestige and social rank become close to being indistinguishable. The current research suggests that, over time, individuals can more readily discern prestige, are more likely to confer deference and, thus, suggest an association between prestige and social rank becomes incredibly strong over time.

One of the hypothesized central cues to a potential learning model's prestige is the attention, deference and followership that they receive from proximate others (Henrich, Chudek, \& Boyd, 2015; Henrich \& Gil-White, 2001). Individuals with high social rank are likely to receive greater attention, deference and followership from their peers and, thus, an individual's social rank should have positive feedback into their prestige over time. The present findings not only provide the first empirical evidence that prestige has a positive temporal effect on social rank, but that social rank also has a strong temporal effect on prestige, emphasizing that the relationship between prestige and social rank is dynamic and the processes may be mutually dependent. Taken together, the present findings suggest that, through this process, the dynamic relationship between prestige and social rank may be wedded together in human hierarchy, highlighting that over time prestige becomes incredibly potent and that social rank also increases an individual's prestige over time. 


\subsection{Limitations and future directions.}

The present findings pose questions as to when exactly dominance is a viable pathway for both attaining and maintaining social rank, and further empirical investigation is needed to directly assess the mechanisms that may level dominance over time. Previous research outlining group mechanisms that level dominance has been theoretical (i.e. Boehm, 2009) and further research should directly test how the outlined mechanisms affect dominance over time, such as through gossip (Feinberg, Cheng, \& Willer, 2012), coalitions (Fessler \& Holbrook, 2013; Gintis et al., 2015), and potentially a concurrent prestige effect (Chudek \& Henrich, 2011; Henrich et al., 2015). Moreover, future research may assess the strategies that those high in dominance may implement to maintain their social rank in light of potential group leveling mechanisms. For example, there may be certain contexts where dominance fares well over time, such as when operating in dyads (Ridgeway, 2017); or when group size is large and relatively fragmented, and members share the diffused costs inflicted by dominant individuals and thus show a great willingness to tolerate them; when individuals have formalized power (Magee \& Galinsky, 2008); when groups are directly competing against neighboring others and dominance is potentially complemented by an individual's perceived competence in outcompeting or inflicting harm against the outgroup (i.e.(Cheng et al., 2010; Halevy, Bornstein, \& Sagiv, 2008); or in groups where dominance-related traits are promoted by social norms (Henry et al., 2000; Redhead, 2016). Moreover, dominant individuals may attempt to ostracize their competition (Case \& Maner, 2014), and may potentially modify the structure of a group so as to prevent group leveling mechanisms from having an impact on their position.

In terms of the modelling approach, while stable individual differences and common causes have been accounted for, reducing the possibility of spurious cross-effect results, with 
observational data causality is never clear. We cannot determine whether it is precisely changes in social rank that cause changes in prestige, or whether it is rather changes in something highly related to social rank. Moreover, the scales used to measure prestige, dominance and social rank were created and tested using a between-subjects application (Cheng et al., 2010). Future research assessing and validating the current scales and their within-subject temporal relationships would further disentangle how measures distinctly load onto the latent concepts of prestige, dominance and social rank.

A key limitation of the current research is the reliance on North American undergraduate students in assessing the proposed evolutionary framework. This population is often not representative of the world's populations (Henrich, Heine, \& Norenzayan, 2010). Whilst there has been previous research assessing the effects of prestige and dominance on rank attainment a number of populations, such as the Tsimane of Bolivia (von Rueden et al., 2010), the Chabu of Ethiopia (Garfield \& Hagan, Under Review), in a developmental setting in rural Romania (Redhead, 2016) and the United States and Canada (Cheng et al., 2013, 2010; Johnson, Burk, \& Kirkpatrick, 2007), all studies have been cross-sectional. Thus, despite an important advantage of providing larger sample sizes for more accurate parameter estimates and the ability to track groups from the point of their formation, the current taskgroup setting potentially limits the processes discussed to the dynamic relationship between prestige, dominance and social rank to task-groups in WEIRD settings or to these processes during young adulthood.

Future research investigating the temporal dynamics of prestige, dominance and social rank is needed on a broader timescale that encompasses multiple ages among geographically and culturally diverse societies to further generalize how effective both routes are for attaining and maintaining social rank in human groups and ascertain when dominance 
becomes a long-term strategy for maintaining social rank. Through this, such future research may further capture the effects of prestige and dominance in different tasks over time and further measure dominance in contexts where aggression is potent and more dramatic displays of dominance and aggressive intent may be observed. Future research may also provide a further understanding of the generalizability of the present results over a longer timescale, as multiple observations spanning years may exhibit less temporal stability than that observed in the current design.

\section{Conclusion.}

In conclusion, the current research provides the first empirical assessment of the longitudinal relationships between prestige, dominance and social rank. The present findings offer support for both dominance and prestige being effective in initial rank attainment but suggest that only prestige is an effective process for maintaining social rank over time. Moreover, the current research delivers considerable insight—-both theoretically and methodologically — into the complex temporal dynamics of prestige, dominance and social rank by presenting and substantiating a longitudinal framework for understanding human social hierarchy. 


\section{Reference List}

Ames, D. R., \& Flynn, F. J. (2007). What breaks a leader: the curvilinear relation between assertiveness and leadership. Journal of Personality and Social Psychology, 92(2), 307.

Anderson, C., \& Kilduff, G. J. (2009a). The Pursuit of Status in Social Groups. Current Directions in Psychological Science, 18(5), 295-298. https://doi.org/10.1111/j.1467-8721.2009.01655.x

Anderson, C., \& Kilduff, G. J. (2009b). Why do dominant personalities attain influence in face-toface groups? The competence-signaling effects of trait dominance. Journal of Personality and Social Psychology, 96(2), 491.

Anderson, C., \& Shirako, A. (2008). Are individuals' reputations related to their history of behavior? Journal of Personality and Social Psychology, 94(2), 320.

Anderson, C., willer, R., Kilduff, G. J., \& brown, C. (2012). The origins of deference: When do people prefer lower status? Journal of Personality and Social Psychology, 102(5), 10771088.

Bakker, R. M. (2010). Taking stock of temporary organizational forms: A systematic review and research agenda. International Journal of Management Reviews, 12, 466-486. http://doi.org/10.1111/j.1468-2370.2010.00281.x

Barkow, J. H. (1975). Prestige and Culture: A Biosocial Interpretation. Current Anthropology, 16(4), 553-572. https://doi.org/10.1086/201619

Baumeister, R. F., Zhang, L., \& Vohs, K. D. (2004). Gossip as cultural learning. Review of General Psychology, 8(2), 111.

Bendersky, C., \& Hays, N. A. (2011). Status Conflict in Groups. Organization Science, 23(2), 323340. https://doi.org/10.1287/orsc. 1110.0734

Berger, J., Rosenholtz, S. J., \& Morris Zelditch, J. (1980). Status Organizing Processes. Annual Review of Sociology, 6(1), 479-508. https://doi.org/10.1146/annurev.so.06.080180.002403

Birch, S. A. J., Vauthier, S. A., \& Bloom, P. (2008). Three- and four-year-olds spontaneously use others' past performance to guide their learning. Cognition, 107(3), 1018-1034. https://doi.org/10.1016/j.cognition.2007.12.008

Bliege Bird, R., \& Smith, E. (2005). Signaling theory, strategic interaction, and symbolic capital. Current Anthropology, 46(2), 221-248.

Boehm, C. (2009). Hierarchy in the Forest: The Evolution of Egalitarian Behavior. Harvard University Press.

Boehm, C., \& Flack, J. C. (2010). The emergence of simple and complex power structures through social niche construction. In The social psychology of power (pp. 46-86). New York, NY: Guilford Press.

Borgerhoff Mulder, M. (1987). On cultural and reproductive success: Kipsigis evidence. American Anthropologist, 89(3), 617-634.

Boyd, R., \& Richerson, P. J. (1988). Culture and the evolutionary process. University of Chicago Press.

Brass, D. J., \& Burkhardt, M. E. (1993). Potential Power and Power Use: An Investigation of Structure and Behavior. Academy of Management Journal, 36(3), 441-470. https://doi.org/10.2307/256588

Bruckert, L., Liénard, J.-S., Lacroix, A., Kreutzer, M., \& Leboucher, G. (2006). Women use voice parameters to assess men's characteristics. Proceedings of the Royal Society of London B: Biological Sciences, 273(1582), 83-89. https://doi.org/10.1098/rspb.2005.3265

Burt, R. S., \& Knez, M. (1996). Trust and third-party gossip. Trust in Organizations: Frontiers of Theory and Research, 68, 89.

Buss, D. M., \& Duntley, J. D. (2006). The evolution of aggression. Evolution and Social Psychology, 263-286.

Case, C. R., \& Maner, J. K. (2014). Divide and conquer: When and why leaders undermine the 
cohesive fabric of their group. Journal of Personality and Social Psychology, 107(6), 1033. Chagnon, N. (2012). The Yanomamo. Nelson Education.

Chapais, B. (2015). Competence and the Evolutionary Origins of Status and Power in Humans. Human Nature, 26(2), 161-183. https://doi.org/10.1007/s12110-015-9227-6

Cheng, J. T., \& Tracy, J. L. (2014). Toward a unified science of hierarchy: Dominance and prestige are two fundamental pathways to human social rank. In The psychology of social status (pp. $3-27)$. Springer.

Cheng, J. T., Tracy, J. L., Foulsham, T., Kingstone, A., \& Henrich, J. (2013). Two ways to the top: Evidence that dominance and prestige are distinct yet viable avenues to social rank and influence. Journal of Personality and Social Psychology, 104(1), 103.

Cheng, J. T., Tracy, J. L., \& Henrich, J. (2010). Pride, personality, and the evolutionary foundations of human social status. Evolution and Human Behavior, 31(5), 334-347. https://doi.org/10.1016/j.evolhumbehav.2010.02.004

Cheng, J. T., Tracy, J. L., Ho, S., \& Henrich, J. (2016). Listen, follow me: Dynamic vocal signals of dominance predict emergent social rank in humans. Journal of Experimental Psychology: General, 145(5), 536.

Chudek, M., \& Henrich, J. (2011). Culture-gene coevolution, norm-psychology and the emergence of human prosociality. Trends in Cognitive Sciences, 15(5), 218-226. https://doi.org/10.1016/j.tics.2011.03.003

Clutton-Brock, T. (2009). Cooperation between non-kin in animal societies. Nature, 462(7269), 5157. https://doi.org/10.1038/nature08366

Decker, S. H., \& Van Winkle, B. (1996). Life in the gang: Family, friends, and violence. Cambridge University Press.

Driver, C. C., Oud, J. H., \& Voelkle, M. C. (2017). Continuous time structural equation modeling with R package ctsem. Journal of Statistical Software, 77(5).

Driver, C. C., \& Voelkle, M. C. (in press). Hierarchical Bayesian Continuous Time Dynamic Modeling. Psychological Methods.

Dunbar, R. (1996). Groups, Gossip, and the Evolution of Language. In New Aspects of Human Ethology (pp. 77-89). Springer, Boston, MA. https://doi.org/10.1007/978-0-585-34289-4_5

Faris, R., \& Felmlee, D. (2011). Status Struggles: Network Centrality and Gender Segregation in Same- and Cross-Gender Aggression. American Sociological Review, 76(1), 48-73. https://doi.org/10.1177/0003122410396196

Feinberg, D. R., Jones, B. C., Little, A. C., Burt, D. M., \& Perrett, D. I. (2005). Manipulations of fundamental and formant frequencies influence the attractiveness of human male voices. Animal Behavior, 69(3), 561-568. https://doi.org/10.1016/j.anbehav.2004.06.012

Feinberg, M., Cheng, J. T., \& Willer, R. (2012). Gossip as an effective and low-cost form of punishment. Behavioral and Brain Sciences, 35(1), 25-25. https://doi.org/10.1017/S0140525X11001233

Fessler, D. M. T., \& Holbrook, C. (2013). Friends Shrink Foes: The Presence of Comrades Decreases the Envisioned Physical Formidability of an Opponent. Psychological Science, 24(5), 797-802. https://doi.org/10.1177/0956797612461508

Gintis, H., van Schaik, C., \& Boehm, C. (2015). Zoon Politikon: The Evolutionary Origins of Human Political Systems. Current Anthropology, 56(3), 327-353. https://doi.org/10.1086/681217

Glowacki, L., \& von Rueden, C. (2015). Leadership solves collective action problems in small-scale societies. Phil. Trans. R. Soc. B, 370(1683), 20150010. https://doi.org/10.1098/rstb.2015.0010

Griskevicius, V., Tybur, J. M., Gangestad, S. W., Perea, E. F., Shapiro, J. R., \& Kenrick, D. T. (2009). Aggress to impress: hostility as an evolved context-dependent strategy. Journal of Personality and Social Psychology, 96(5), 980.

Halevy, N., Bornstein, G., \& Sagiv, L. (2008). "In-group love" and "out-group hate" as motives for individual participation in intergroup conflict: A new game paradigm. Psychological Science, 
19(4), 405-411.

Hardy, C. L., \& Van Vugt, M. (2006). Nice Guys Finish First: The Competitive Altruism Hypothesis. Personality and Social Psychology Bulletin, 32(10), 1402-1413. https://doi.org/10.1177/0146167206291006

Hawkes, K., \& Bliege Bird, R. (2002). Showing off, handicap signaling, and the evolution of men's work. Evolutionary Anthropology: Issues, News, and Reviews: Issues, News, and Reviews, 11(2), 58-67.

Hawley, P. H. (1999). The Ontogenesis of Social Dominance: A Strategy-Based Evolutionary Perspective. Developmental Review, 19(1), 97-132. https://doi.org/10.1006/drev.1998.0470

Hawley, P. H., Little, T. D., \& Card, N. A. (2007). The allure of a mean friend: Relationship quality and processes of aggressive adolescents with prosocial skills. International Journal of Behavioral Development, 31(2), 170-180. https://doi.org/10.1177/0165025407074630

Henrich, J. (2016). The secret of our success: How learning from others drove human evolution, domesticated our species, and made us smart.

Henrich, J., \& Broesch, J. (2011). On the nature of cultural transmission networks: evidence from Fijian villages for adaptive learning biases. Philosophical Transactions of the Royal Society of London B: Biological Sciences, 366(1567), 1139-1148.

Henrich, J., Chudek, M., \& Boyd, R. (2015). The Big Man Mechanism: how prestige fosters cooperation and creates prosocial leaders. Phil. Trans. R. Soc. B, 370(1683), 20150013. https://doi.org/10.1098/rstb.2015.0013

Henrich, J., \& Gil-White, F. J. (2001). The evolution of prestige: freely conferred deference as a mechanism for enhancing the benefits of cultural transmission. Evolution and Human Behavior, 22(3), 165-196. https://doi.org/10.1016/S1090-5138(00)00071-4

Henrich, J., Heine, S. J., \& Norenzayan, A. (2010). Most people are not WEIRD. Nature, 466(7302), 29-29. https://doi.org/10.1038/466029a

Henrich, J., \& McElreath, R. (2003). The evolution of cultural evolution. Evolutionary Anthropology: Issues, News, and Reviews, 12(3), 123-135. https://doi.org/10.1002/evan.10110

Henry, D., Guerra, N., Huesmann, R., Tolan, P., VanAcker, R., \& Eron, L. (2000). Normative Influences on Aggression in Urban Elementary School Classrooms. American Journal of Community Psychology, 28(1), 59-81. https://doi.org/10.1023/A:1005142429725

Hoffman, M. D., \& Gelman, A. (2011). The No-U-Turn Sampler: Adaptively Setting Path Lengths in Hamiltonian Monte Carlo." arXiv, 1111 (4246). URL http://arxiv. org/abs/1111, 4246.

Holbrook, C., Fessler, D. M., \& Navarrete, C. D. (2016). Looming large in others' eyes: Racial stereotypes illuminate dual adaptations for representing threat versus prestige as physical size. Evolution and Human Behavior, 37(1), 67-78.

Johnson, R. T., Burk, J. A., \& Kirkpatrick, L. A. (2007). Dominance and prestige as differential predictors of aggression and testosterone levels in men. Evolution and Human Behavior, 28(5), 345-351. https://doi.org/10.1016/j.evolhumbehav.2007.04.003

Keltner, D., Young, R. C., Heerey, E. A., Oemig, C., \& Monarch, N. D. (1998). Teasing in hierarchical and intimate relations. Journal of Personality and Social Psychology, 75(5), 1231.

Leavitt, H. (2005). Top down: Why hierarchies are here to stay and how to manage them more effectively. Harvard Business Press.

Lewandowski, D., Kurowicka, D., \& Joe, H. (2009). Generating random correlation matrices based on vines and extended onion method. Journal of multivariate analysis, 100(9), 1989-2001.

Little, A. C., Burriss, R. P., Jones, B. C., \& Roberts, S. C. (2007). Facial appearance affects voting decisions. Evolution and Human Behavior, 28(1), 18-27. https://doi.org/10.1016/j.evolhumbehav.2006.09.002

Losin, E. A. R., Iacoboni, M., Martin, A., \& Dapretto, M. (2012). Own-gender imitation activates the brain's reward circuitry. Social Cognitive and Affective Neuroscience, 7(7), 804-810. https://doi.org/10.1093/scan/nsr055 
Lukaszewski, A. W., Simmons, Z. L., Anderson, C., \& Roney, J. R. (2016). The role of physical formidability in human social status allocation. Journal of Personality and Social Psychology, 110(3), 385.

Macfarlan, S. J., Quinlan, R., \& Remiker, M. (2013). Cooperative behavior and prosocial reputation dynamics in a Dominican village. Proceedings of the Royal Society of London B: Biological Sciences, 280(1761). https://doi.org/10.1098/rspb.2013.0557

Magee, J. C., \& Galinsky, A. D. (2008). Social Hierarchy: The Self-Reinforcing Nature of Power and Status. Academy of Management Annals, 2(1), 351-398. https://doi.org/10.1080/19416520802211628

Manson, J. H., Gervais, M. M., Fessler, D. M. T., \& Kline, M. A. (2014). Subclinical Primary Psychopathy, but Not Physical Formidability or Attractiveness, Predicts Conversational Dominance in a Zero-Acquaintance Situation. PLOS ONE, 9(11), e113135. https://doi.org/10.1371/journal.pone.0113135

Mazur, A. (1985). A Biosocial Model of Status in Face-to-Face Primate Groups. Social Forces, 64(2), 377-402. https://doi.org/10.1093/sf/64.2.377

O'Gorman, R., Henrich, J., \& Vugt, M. V. (2009). Constraining free riding in public goods games: designated solitary punishers can sustain human cooperation. Proceedings of the Royal Society of London B: Biological Sciences, 276(1655), 323-329. https://doi.org/10.1098/rspb.2008.1082

Pandit, S. A., \& van Schaik, C. (2003). A model for leveling coalitions among primate males: toward a theory of egalitarianism. Behavioral Ecology and Sociobiology, 55(2), 161-168. https://doi.org/10.1007/s00265-003-0692-2

Pellegrini, A. D., \& Long, J. D. (2003). A sexual selection theory longitudinal analysis of sexual segregation and integration in early adolescence. Journal of Experimental Child Psychology, 85(3), 257-278. https://doi.org/10.1016/S0022-0965(03)00060-2

Power, E. A., \& Ready, E. (2018). Building bigness: reputation, prominence, and social capital in rural South India. American Anthropologist.

Redhead, D. (2016). Social Hierarchy \& Social Networks: The Effects of Prestige and Dominance within a Developmental Context (Masters). Durham University. Retrieved from http://etheses.dur.ac.uk/11761/

Redhead, D., Cheng, J. T., \& O'Gorman, R. (2018). Status Competition and Peer Relationships in Childhood. In T. Shackelford \& V. Weekes-Shackelford (Eds.), Encyclopedia of Evolutionary Psychological Science. AG: Springer International Publishing.

Redhead, D., Cheng, J. T., \& O'Gorman, R. (2019). Higher Status in Groups. In T. Shackelford \& V. Weekes-Shackelford (Eds.), Encyclopedia of Evolutionary Psychological Science. AG: Springer International Publishing.

Sell, A., Cosmides, L., Tooby, J., Sznycer, D., Rueden, C. von, \& Gurven, M. (2009). Human adaptations for the visual assessment of strength and fighting ability from the body and face. Proceedings of the Royal Society of London B: Biological Sciences, 276(1656), 575-584. https://doi.org/10.1098/rspb.2008.1177

Sijtsema, J. J., Veenstra, R., Lindenberg, S., \& Salmivalli, C. (2009). Empirical test of bullies' status goals: assessing direct goals, aggression, and prestige. Aggressive Behavior, 35(1), 57-67. https://doi.org/10.1002/ab.20282

Stan Development Team. 2018. RStan: the R interface to Stan. R package version 2.17.3. http://mcstan.org

Van Vugt, M., Hogan, R., \& Kaiser, R. (2008). Leadership, followership, and evolution: Some lessons from the past. American Psychologist, 63(3), 182-196.

von Rueden, C., Gurven, M., \& Kaplan, H. (2010). Why do men seek status? Fitness payoffs to dominance and prestige. Proceedings of the Royal Society of London B: Biological Sciences, rspb20102145. https://doi.org/10.1098/rspb.2010.2145

von Rueden, C., \& Jaeggi, A. V. (2016). Men's status and reproductive success in 33 nonindustrial societies: Effects of subsistence, marriage system, and reproductive strategy. Proceedings of 
the National Academy of Sciences, 113(39), 10824-10829.

https://doi.org/10.1073/pnas.1606800113

Wiessner, P., \& Schiefenhövel, W. (1998). Food and the Status Quest: An Interdisciplinary Perspective. Berghahn Books.

Wiggins, J. S., Trapnell, P., \& Phillips, N. (1988). Psychometric and Geometric Characteristics of the Revised Interpersonal Adjective Scales (IAS-R). Multivariate Behavioral Research, 23(4), 517-530. https://doi.org/10.1207/s15327906mbr2304_8 


\section{Equations}

Equation 1. Matrix specification of the subject-level model for the relationships between social rank, dominance and prestige. Notations that are underbraced represent both the matrix name specified in the ctsem model and also the symbol used in formulas outlined in Driver \& Voelkle (2018). See Driver \& Voelkle (2018) for a formal outline of the ctsem model.

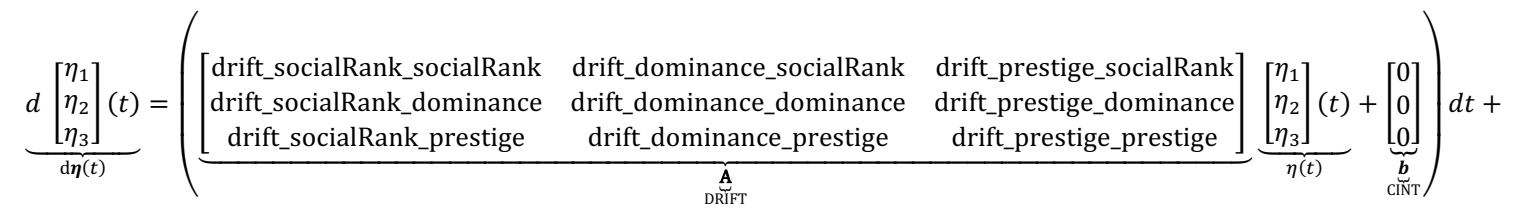

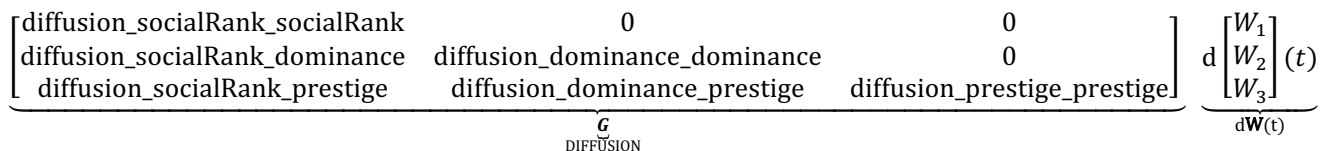

$$
\underbrace{\left[\begin{array}{l}
Y_{1} \\
Y_{2} \\
Y_{3}
\end{array}\right](t)}_{\mathbf{Y}(t)}=\underbrace{\left[\begin{array}{lll}
1 & 0 & 0 \\
0 & 1 & 0 \\
0 & 0 & 1
\end{array}\right]}_{\text {LAM̆BDA }} \underbrace{\left[\begin{array}{l}
\eta_{1} \\
\eta_{2} \\
\eta_{3}
\end{array}\right](t)}_{\boldsymbol{\eta}(t)}+\underbrace{\left[\begin{array}{c}
\text { manifestmeans_socialRank } \\
\text { manifestmeans_dominance } \\
\text { manifestmeans_prestige }
\end{array}\right]}_{\text {MANIFSSTMEANS }}+\underbrace{\left[\begin{array}{l}
\epsilon_{1} \\
\epsilon_{2} \\
\epsilon_{3}
\end{array}\right](t)}_{\boldsymbol{\epsilon}(t)}
$$

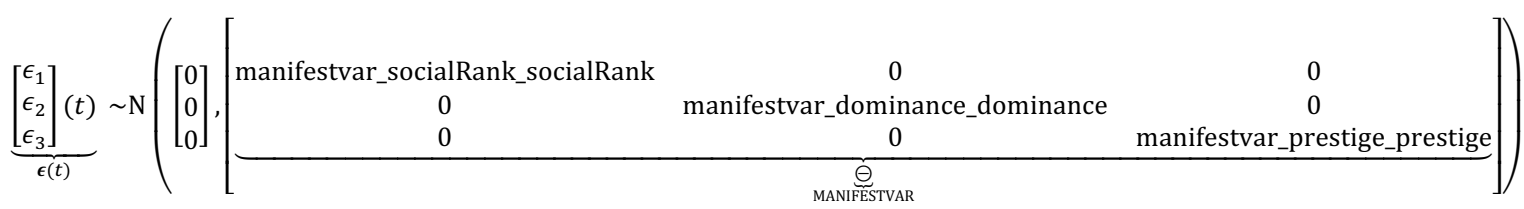




\section{Tables}

Table 1.

Descriptive statistics for all variables.

\begin{tabular}{lccccc}
\hline Variable & $n$ & Mean $(S D)$ & Median & Min & Max \\
\hline Prestige $T_{1}$ & 259 & $5.04(0.76)$ & 5.06 & 2.36 & 7.00 \\
Prestige $T_{2}$ & 256 & $4.87(1.00)$ & 4.88 & 1.00 & 7.00 \\
Prestige $T_{3}$ & 250 & $5.03(1.04)$ & 5.08 & 1.25 & 7.00 \\
Prestige $T_{4}$ & 249 & $5.09(1.07)$ & 5.17 & 2.00 & 7.00 \\
Dominance $T_{1}$ & 259 & $2.80(0.62)$ & 2.75 & 1.62 & 5.50 \\
Dominance $T_{2}$ & 256 & $2.64(0.85)$ & 2.62 & 1.00 & 6.00 \\
Dominance $T_{3}$ & 250 & $2.68(0.94)$ & 2.62 & 1.00 & 6.50 \\
Dominance $T_{4}$ & 249 & $2.61(0.96)$ & 2.62 & 1.00 & 5.62 \\
Social Rank $T_{1}$ & 259 & $4.56(0.93)$ & 4.67 & 1.83 & 6.67 \\
Social Rank $T_{2}$ & 256 & $4.63(1.00)$ & 4.82 & 1.00 & 6.79 \\
Social Rank $T_{3}$ & 250 & $4.90(0.98)$ & 5.08 & 1.17 & 7.00 \\
Social Rank $T_{4}$ & 249 & $4.95(0.94)$ & 5.00 & 2.25 & 6.92 \\
Gender ${ }^{a}$ & 262 & $0.60(0.49)$ & - & 0.00 & 1.00 \\
\hline
\end{tabular}

Note. $N=263$.

Total percentage of missing data $=14.54 \%$.

a. Males were coded 0 , females coded 1 . 
Table 2.

Means, standard deviations and posterior credibility intervals $(C I)$ for means of estimated population distributions.

\begin{tabular}{|c|c|c|c|c|c|c|c|c|c|c|}
\hline \multirow[b]{3}{*}{ Parameter } & \multicolumn{10}{|c|}{ Dependent Process } \\
\hline & \multicolumn{4}{|c|}{ Social Rank } & \multicolumn{3}{|c|}{ Dominance } & \multicolumn{3}{|c|}{ Prestige } \\
\hline & $\bar{x}$ & $S D$ & {$[2.5 \%$} & $7.5 \%]$ & $\bar{x}$ & $S D$ & $\begin{array}{c}C I \\
{[2.5 \%, 97.5 \%]}\end{array}$ & $\bar{x}$ & $S D$ & $\begin{array}{c}C I \\
{[2.5 \%,} \\
97.5 \%]\end{array}$ \\
\hline$T_{0}$ Mean & -0.66 & 0.57 & {$[-1.4$} & $0.85]$ & 0.19 & 1.20 & {$[-1.54,3.72]$} & -0.82 & 0.54 & $\begin{array}{c}{[-1.73,} \\
0.65]\end{array}$ \\
\hline $\begin{array}{l}\text { Manifest } \\
\text { Means }\end{array}$ & 5.13 & 0.58 & {$[3.6$} & $5.93]$ & 2.53 & 1.20 & {$[-1.01,4.24]$} & 5.34 & 0.54 & $\begin{array}{l}{[3.89} \\
6.25]\end{array}$ \\
\hline $\begin{array}{l}\text { Manifest } \\
\text { Variance }\end{array}$ & 0.28 & 0.06 & {$[0.1$} & $.36]$ & 0.47 & 0.04 & {$[0.38,0.54]$} & 0.25 & 0.10 & $\begin{array}{l}{[0.02} \\
0.38]\end{array}$ \\
\hline $\begin{array}{l}\text { Main Effect } \\
\text { of Gender }^{\text {a }}\end{array}$ & 0.14 & 0.10 & {$[-0.6$} & $0.32]$ & -0.13 & 0.09 & {$[-0.30,0.04]$} & 0.14 & 0.10 & $\begin{array}{c}{[-0.60} \\
0.33]\end{array}$ \\
\hline \multicolumn{11}{|c|}{ Between-subject Parameters ${ }^{b}$} \\
\hline Social Rank & - & - & & & - & - & - & - & - & - \\
\hline Dominance & -0.02 & 0.20 & {$[-0.4$} & $0.31]$ & - & - & - & - & - & - \\
\hline Prestige & 0.78 & 0.12 & {$[0.4$} & $0.90]$ & -0.28 & 0.24 & {$[-0.81,0.17]$} & - & - & - \\
\hline \multicolumn{11}{|c|}{ Drift Parameters } \\
\hline Social Rank & -0.66 & 0.19 & {$[-1.0$} & $0.32]$ & 0.16 & 0.15 & {$[-0.11,0.47]$} & 1.10 & 0.23 & $\begin{array}{l}{[0.66} \\
1.58]\end{array}$ \\
\hline Dominance & 0.12 & 0.12 & {$[-0.1$} & $0.38]$ & -0.23 & 0.16 & {$[-0.59,-0.02]$} & -0.20 & 0.16 & $\begin{array}{c}{[-0.50} \\
0.11]\end{array}$ \\
\hline Prestige & 0.33 & 0.15 & {$[0.0$} & $0.66]$ & -0.05 & 0.13 & {$[-0.31,0.20]$} & -1.07 & 0.22 & $\begin{array}{c}{[-1.52,-} \\
0.66]\end{array}$ \\
\hline \multicolumn{11}{|c|}{ Diffusion Parameters } \\
\hline Social Rank & 0.62 & 0.07 & 0.50 & 0.79 & - & - & - & - & - & - \\
\hline Dominance & -0.03 & 0.12 & -0.25 & 0.20 & 0.50 & 0.11 & {$[0.32,0.74]$} & - & - & - \\
\hline Prestige & 0.71 & 0.12 & 0.46 & 0.90 & -0.22 & 0.18 & {$[-0.60,0.14]$} & 0.74 & 0.11 & $\begin{array}{l}{[0.55,} \\
0.94]\end{array}$ \\
\hline
\end{tabular}

Note. $N=263 . T=4$.

a. Gender was coded 0 for males and 1 for females. Thus, a positive parameter indicates that being female had a positive main effect on the process, whilst a negative parameter would suggest that being male had a positive effect on the process.

b. Between-subject parameters are the standardized population correlations. 


\section{Figures}

Figure 1. A triadic (three-process) continuous time structural equation model. The model comprises 3 manifest variables (dominance, social rank and prestige) and one timeindependent predictor (gender). Black circles indicate the latent continuous time processes that load onto the 3 manifest variables. Regression paths are solid black lines between variables or processes, variance/covariance paths are dashed black lines between variables or processes and light grey paths represent those constrained to a function of other parameters. Manifest intercepts are not represented.

$\mathrm{D}=$ Dominance

Gen $=$ Gender

$\mathrm{P}=$ Prestige

$\mathrm{SR}=$ Social Rank

$\mathrm{T}=$ Time Point

Figure 2. Bayesian estimates of partial correlations between social rank, prestige and dominance at all waves during the study. Variable names are presented on the diagonal of the figure. The number associated with the variable names indicates the wave of observation (i.e. between wave 1 and 4 ).

$\mathrm{SR}=$ Social Rank

$\mathrm{D}=$ Dominance

$\mathrm{P}=$ Prestige

Figure 3a-d. Posterior mean and credibility intervals for autoregression and drift effects between prestige, dominance and social rank. Figure 3 a outlines the autoregression effects of the processes on themselves, representing the persistence of changes in a process. Figure $3 \mathrm{~b}$ plots the drift effects of dominance and prestige on social rank. The drift effects of dominance and social rank on prestige are presented in Figure 3c, whilst Figure 3d outlines the effects of social rank and prestige on dominance. 


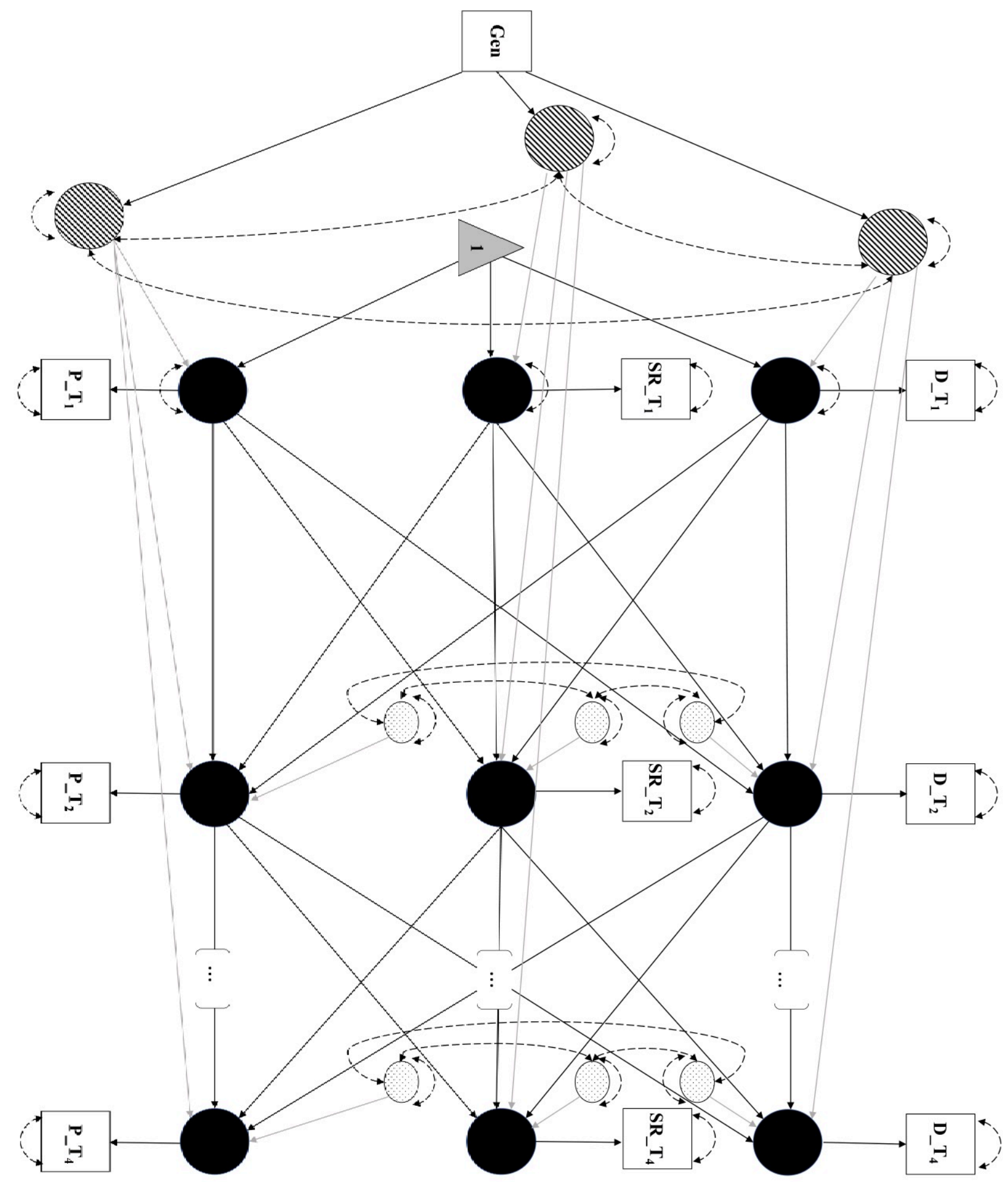




\begin{tabular}{|c|c|c|c|c|c|c|c|c|c|c|c|}
\hline SR1 & & & & & & & & & & & \\
\hline 0.43 & SR2 & & & & & & & & & & \\
\hline 0.19 & 0.14 & SR3 & & & & & & & & & \\
\hline-0.06 & 0.18 & 0.45 & SR4 & & & & & & & & \\
\hline 0.2 & -0.12 & 0.04 & -0.03 & D1 & & & & & & & \\
\hline 0.07 & 0.12 & -0.04 & -0.06 & 0.25 & D2 & & & & & & \\
\hline-0.03 & -0.02 & 0.12 & 0.08 & 0.14 & 0.33 & D3 & & & & & \\
\hline 0.01 & 0.08 & -0.11 & 0.05 & 0.12 & 0.24 & 0.4 & D4 & & & & \\
\hline 0.32 & -0.24 & 0 & 0.13 & -0.08 & 0.05 & -0.01 & -0.12 & P1 & & & \\
\hline-0.19 & 0.69 & -0.12 & -0.13 & 0.09 & -0.2 & 0.08 & -0.01 & 0.26 & P2 & & \\
\hline-0.06 & -0.04 & 0.53 & -0.18 & -0.09 & -0.02 & -0.08 & 0.08 & 0.08 & 0.25 & P3 & \\
\hline 0.05 & -0.05 & -0.14 & 0.49 & -0.04 & 0.17 & -0.13 & -0.06 & -0.11 & 0.17 & 0.47 & P4 \\
\hline
\end{tabular}




\section{Regression coefficients}

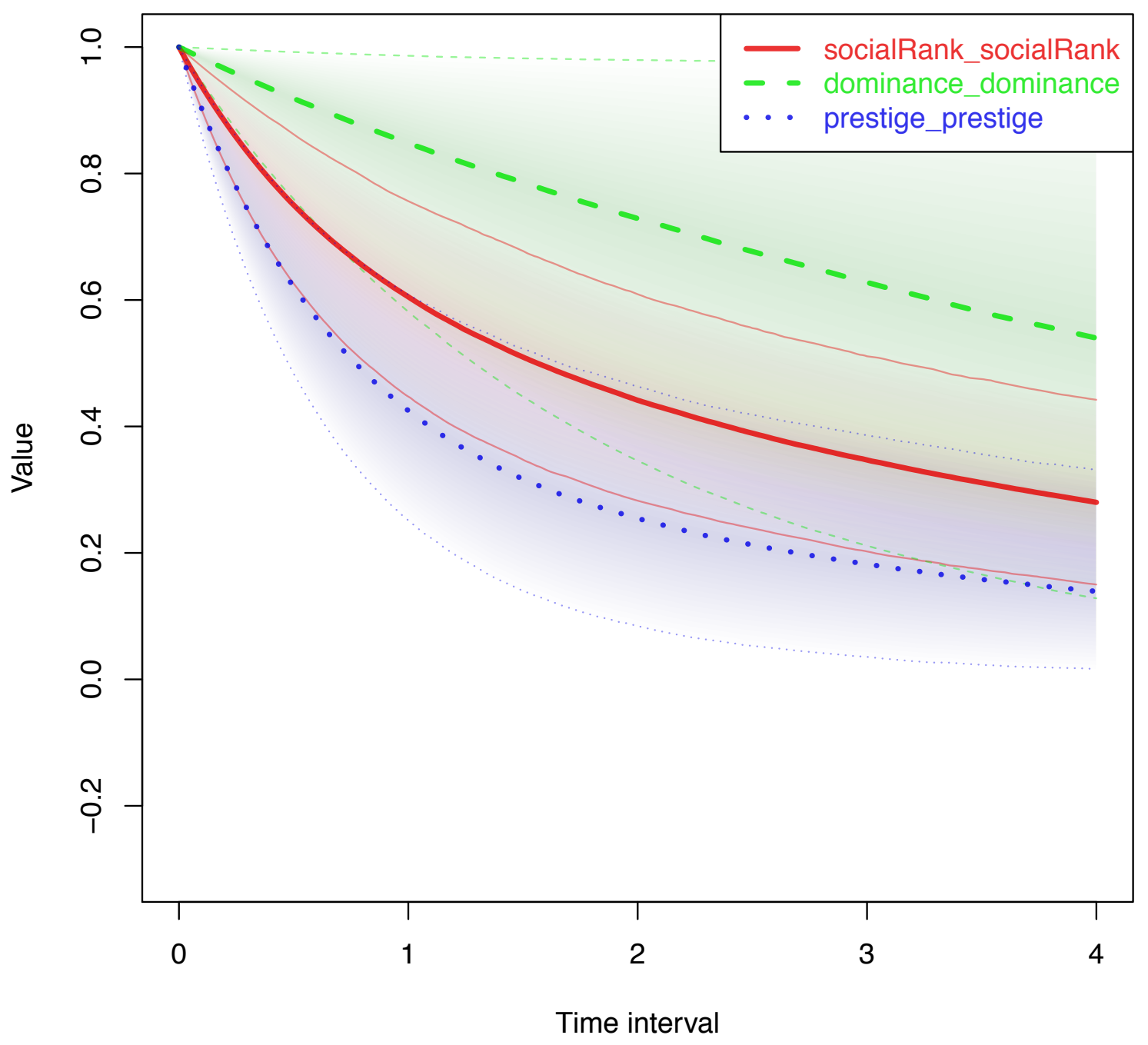




\section{Regression coefficients}






\section{Regression coefficients}

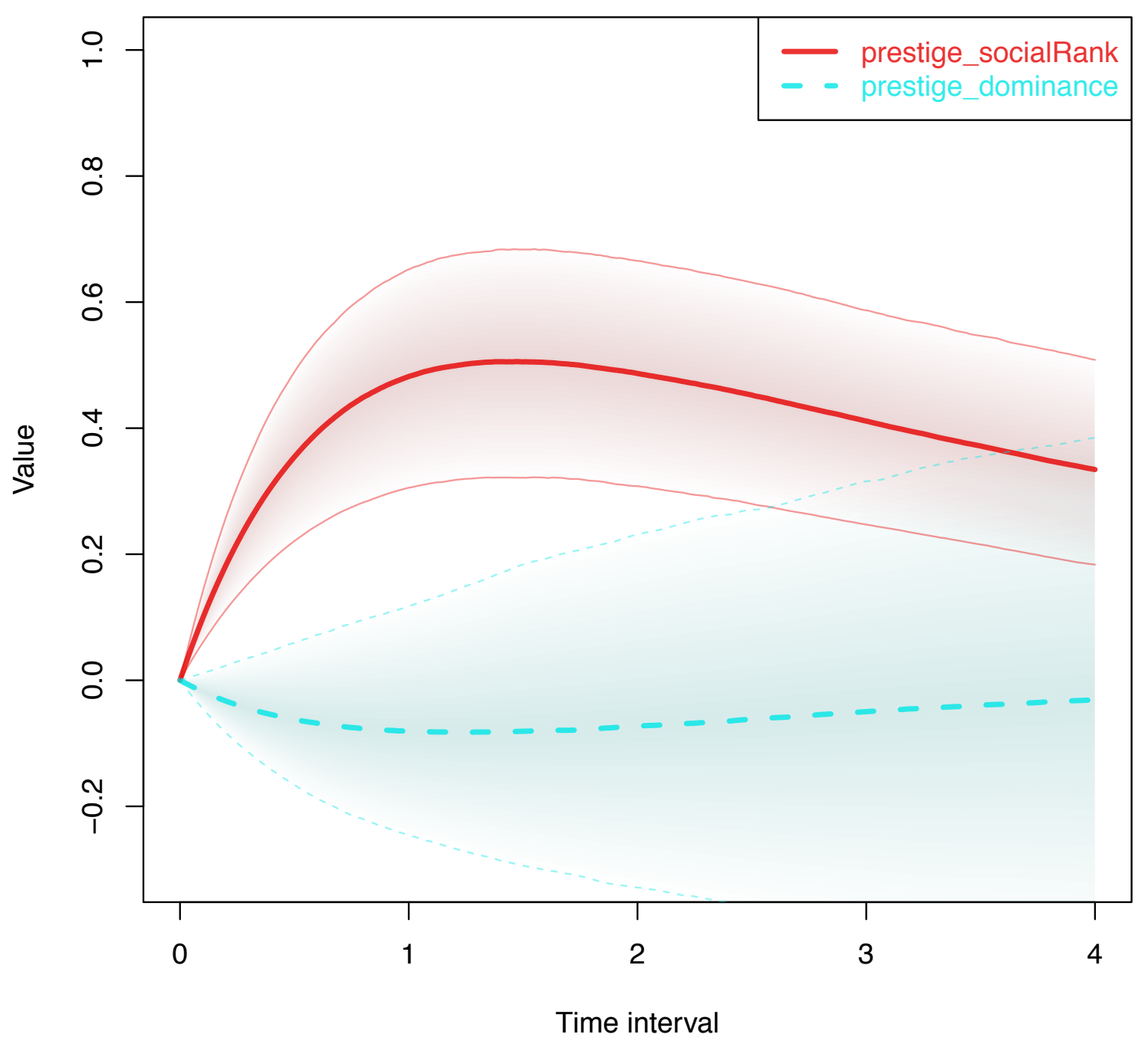




\section{Regression coefficients}

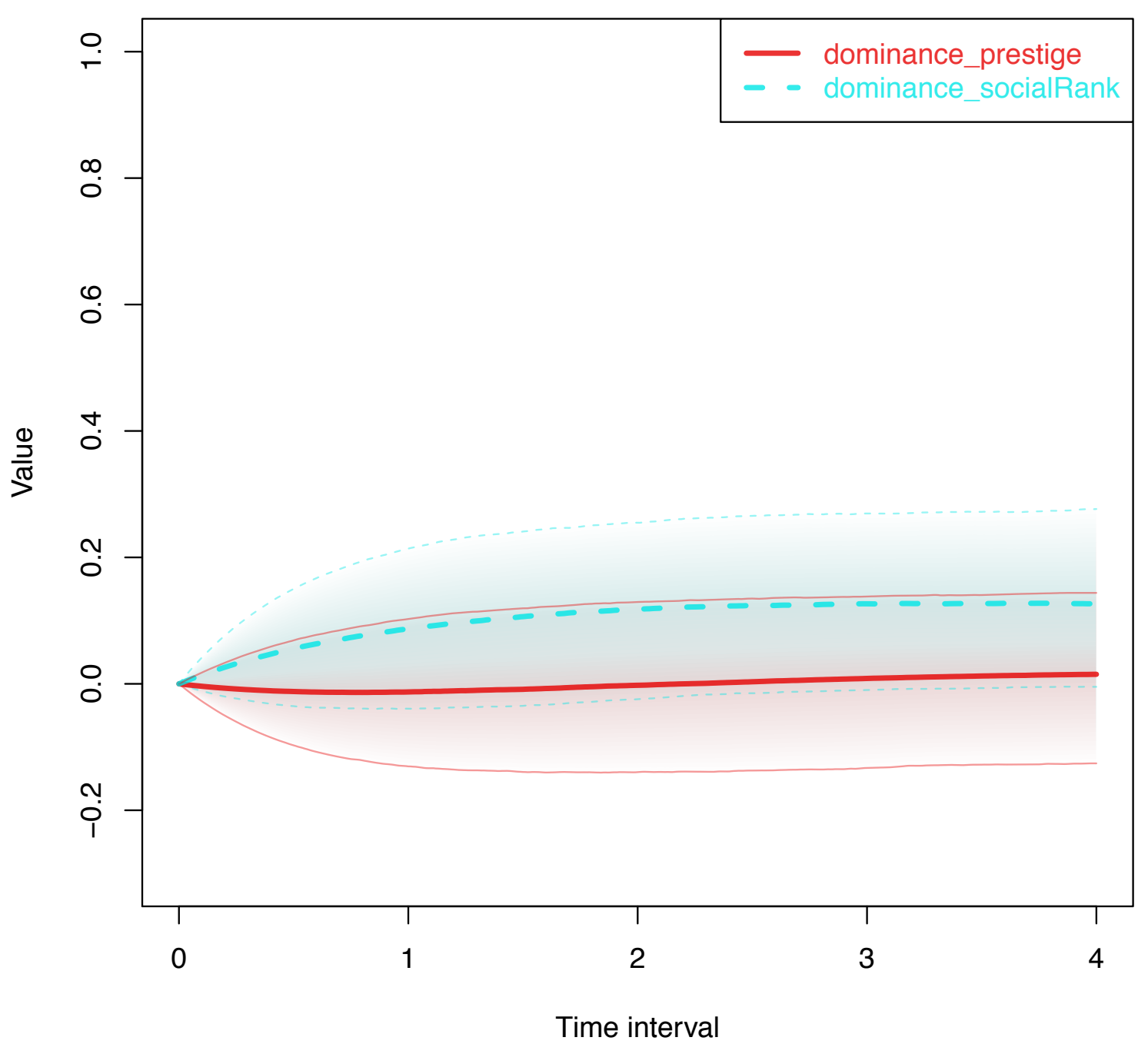




\section{Electronic Supplementary Materials}

for

"On the dynamics of social hierarchy: A longitudinal investigation of the rise and fall of prestige, dominance and social rank in naturalistic task groups"

\section{Peer-Report Measures}

Prestige. To measure prestige participants rated all members of their task group on four items taken from the dominance-prestige scale questionnaires (Cheng, Tracy \& Henrich, 2010). The four items were: "Members of your group respect and admire them", "Their unique talents and abilities are recognized by others in the group", "They are considered an expert on some matters by members of the group", "Members of your group seek his/her advice on a variety of matters". We used an abridged version of the scale to reduce participant fatigue. Use of the abridged scale substantially increased the internal consistency of both measures of prestige and dominance in comparison to the full scale. The abridged scale had a strong correlation $(\rho=.921, \alpha=.97)$ with the full scale that measured a subset of participants in classroom indicating that the measures captured the same variance. The measure had excellent internal consistency throughout the study. In time wave $1, \alpha=.88$, wave $2 \alpha=.89$, wave $3 \alpha=.88$, and in wave $4 \alpha=.90$.

Dominance. Participants rated all members of their task group on four items taken from the dominance-prestige scale questionnaires (Cheng, Tracy \& Henrich, 2010). The four items were: "They enjoy having control over other members of the group", "They often try to get their own way regardless of what others in the group may want", "They are willing to use aggressive tactics to get their way", "They try to control others rather than permit them to control them". Again, use of the abridged scale substantially increased the internal 
consistency of both measures of prestige and dominance in comparison to the full scale. The abridged scale had a strong correlation $(\rho=.939, \alpha=.93)$ with the full scale that measured a subset of participants in classroom indicating that the measures captured the same variance. The measure had excellent internal consistency throughout the study. In time wave $1, \alpha=$ .82 , wave $2 \alpha=.86$, wave $3 \alpha=.91$, and in wave $4 \alpha=.93$.

Social Rank. As outlined in the current manuscript we used previously validated measures of social rank that predict the actual decision-making capacity of members within groups (Cheng et al., 2013). The measure had adequate to good internal consistency throughout the study. In time wave $1, \alpha=.71$, wave $2 \alpha=.79$, wave $3 \alpha=.74$, and in wave $4 \alpha=.68$.

\section{Bivariate Correlations between Prestige, Dominance and Social Rank}

As with the partial correlation matrix, we specified a uniform prior on the space of bivariate correlation matrices. Estimation was carried out using R package Stan and we again used a NUTS sampler with 4 chains and 2000 iterations. All parameters had above 1999 effective samples and an $\widehat{R}$ of 1.00 , indicating appropriate model convergence. As shown in ESM Figure 1, bivariate correlations between prestige and social are positive and substantial at every wave. Bivariate correlations between dominance and social rank were again positive and substantial in the initial wave of measurement $(\rho=0.19, C I=[0.08,0.30])$. However, throughout the remainder of the study the correlation between dominance and social rank was negligible. 
Hierarchical Bayesian continuous-time dynamic modelling was chosen to analyse the current data as it provides several advantages to more traditional discrete time or trajectoryoriented models for longitudinal data (such as multi-level modelling and latent growth curve modelling). Dynamic models comprise a broad range of modelling techniques that assess how processes function within subjects over time. These processes often follow a smooth trajectory, are sequentially dependent (i.e. autocorrelation/autoregression) and are guided by small levels of stochastic inputs (i.e. there is a small amount of randomness in changes over time). These processes also unfold over continuous time and modelling change over time in discrete time points can amount to a number of issues. Discrete time models assume that there are equal time intervals between points of measurement and, in most cases, this assumption is not satisfied, which can cause bias in parameter estimates (de Haan-Rietdijk, Voelkle, Keijsers, \& Hamaker, 2017; Voelkle \& Oud, 2013). These strict assumptions associated with equally spaced periods between measurements further hinder the generalizability of results as comparison between studies that have differently spaced time intervals is not easy. The use of continuous time models overcome these problems by naturally accounting for differing time intervals by explicitly incorporating time interval into the equation, thus estimating latent continuous time parameters and therefore assessing the behaviour of a given processes at any point in time (regardless of whether it is observed or not). Moreover, unlike other approaches, continuous time structural equation models (and other state-space models) parse informative unpredictable fluctuations in the trajectory of the process (innovation variance) — which may be useful for future predictions - from deviations that are not meaningful (measurement error) and do not offer any predictive value (Driver \& Voelkle, 2018). For more comprehensive outlines of dynamic structural equation models see Asparouhov, Hamaker, \& Muthén (2018) and for continuous time structural equation models see Driver, Oud, \& Voelkle (2017) and Voelkle, Oud, Davidov, \& Schmidt (2012) 
Whilst continuous time modelling does overcome many issues relating to modelling longitudinal data, many approaches do not account for the potentially hierarchical nature of temporal processes. More traditional approaches (i.e. autoregressive cross-lagged panel models) often estimate a single set of fixed-parameter effects, which assume that the processes unfold in exactly the same way for all subjects. However, it is common for the intercept in dynamic models to vary between subjects and not accounting for the subjectspecific differences in the average level of a process may bias parameters within the model that are assessing the temporal dynamics (Hamaker, Kuiper, \& Grasman, 2015). The current hierarchical Bayesian approach provides a middle ground between fixed-effects models and subject-specific models by estimating population distributions for model parameters (For a technical outline and mathematical description see Driver \& Voelkle (2018). The present model simultaneously estimates the population distribution mean and variance, which serves as prior information and informs the sampling of the subject level parameters as hyperpriors. Hyperpriors are priors that reflect the expectations for the population distribution. Thus, the subject specific parameter estimates are joint-posterior population distributions that are conditional on a combination of the estimated population distribution, which fully accounts for between-subject differences, and the calculated likelihood of parameters being subject specific. 


\section{References}

Asparouhov, T., Hamaker, E. L., \& Muthén, B. (2018). Dynamic structural equation models. Structural Equation Modeling: A Multidisciplinary Journal, 25(3), 359-388.

de Haan-Rietdijk, S., Voelkle, M. C., Keijsers, L., \& Hamaker, E. L. (2017). Discrete-vs. Continuous-Time Modeling of Unequally Spaced Experience Sampling Method Data. Frontiers in Psychology, 8.

Driver, C. C., Oud, J. H., \& Voelkle, M. C. (2017). Continuous time structural equation modeling with R package ctsem. Journal of Statistical Software, 77(5).

Driver, C. C., \& Voelkle, M. C. (2018). Hierarchical Bayesian continuous time dynamic modeling. Psychological Methods.

Hamaker, E. L., Kuiper, R. M., \& Grasman, R. P. (2015). A critique of the cross-lagged panel model. Psychological Methods, 20(1), 102.

Marsman, M., \& Wagenmakers, E.-J. (2017). Bayesian benefits with JASP. European Journal of Developmental Psychology, 14(5), 545-555. https://doi.org/10.1080/17405629.2016.1259614

Voelkle, M. C., \& Oud, J. H. (2013). Continuous time modelling with individually varying time intervals for oscillating and non-oscillating processes. British Journal of Mathematical and Statistical Psychology, 66(1), 103-126.

Voelkle, M. C., Oud, J. H. L., Davidov, E., \& Schmidt, P. (2012). An SEM approach to continuous time modeling of panel data: relating authoritarianism and anomia. Psychological Methods, 17(2), 176. 


\section{Figures}

Figure 1. Bayesian estimates of bivariate correlations between social rank, prestige and dominance at all waves during the study. Variable names are presented on the diagonal of the figure. The number associated with the variable names indicates the wave of observation (i.e. between wave 1 and 4 ).

$\mathrm{SR}=$ Social Rank

$\mathrm{D}=$ Dominance

$\mathrm{P}=$ Prestige

\begin{tabular}{|c|c|c|c|c|c|c|c|c|c|c|c|}
\hline SR1 & & & & & & & & & & & 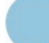 \\
\hline 0.62 & SR2 & & & & & & & 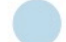 & & & \\
\hline 0.53 & 0.67 & SR3 & & & & & & & & & \\
\hline 0.44 & 0.62 & 0.75 & SR4 & & & & & & & & \\
\hline 0.19 & -0.02 & -0.06 & -0.08 & D1 & & & & & & & \\
\hline 0.24 & 0.12 & 0.04 & 0.06 & 0.49 & D2 & & & & & & \\
\hline 0.19 & 0.14 & 0.09 & 0.09 & 0.45 & 0.59 & D3 & & & & & \\
\hline 0.17 & 0.15 & 0.02 & 0.05 & 0.43 & 0.56 & 0.63 & D4 & & & & \\
\hline 0.36 & 0.25 & 0.31 & 0.29 & -0.09 & -0.05 & -0.06 & -0.13 & P1 & & & \\
\hline 0.44 & 0.82 & 0.58 & 0.53 & -0.09 & -0.05 & 0.03 & 0.03 & 0.34 & P2 & & \\
\hline 0.41 & 0.65 & 0.77 & 0.63 & -0.17 & -0.05 & -0.05 & -0.03 & 0.33 & 0.7 & P3 & \\
\hline 0.39 & 0.62 & 0.66 & 0.73 & -0.15 & 0.02 & -0.05 & -0.03 & 0.26 & 0.64 & 0.78 & P4 \\
\hline
\end{tabular}

